\title{
Polymethoxyflavone Apigenin-Trimethylether Suppresses LPS-Induced Inflammatory Response in Nontransformed Porcine Intestinal Cell Line IPEC-J2
}

\author{
Orsolya Farkas, Orsolya Palócz, Erzsébet Pászti-Gere, and Péter Gálfi \\ Department of Pharmacology and Toxicology, Faculty of Veterinary Science, Szent István University, \\ István utca 2, Budapest 1078, Hungary \\ Correspondence should be addressed to Orsolya Farkas; farkas.orsolya@aotk.szie.hu
}

Received 18 September 2014; Accepted 10 December 2014

Academic Editor: Tullia Maraldi

Copyright (C) 2015 Orsolya Farkas et al. This is an open access article distributed under the Creative Commons Attribution License, which permits unrestricted use, distribution, and reproduction in any medium, provided the original work is properly cited.

\begin{abstract}
The in vitro anti-inflammatory effect of apigenin and its trimethylated analogue (apigenin-trimethylether) has been investigated in order to evaluate whether these flavonoids could attenuate LPS-induced inflammation in IPEC-J2 non-transformed intestinal epithelial cells. Levels of IL-6, IL-8, TNF- $\alpha$, and COX-2 mRNA were measured as a marker of inflammatory response. The extracellular $\mathrm{H}_{2} \mathrm{O}_{2}$ level in IPEC-J2 cells was also monitored by Amplex Red assay. Our data revealed that both compounds had significant lowering effect on the inflammatory response. Apigenin (at $25 \mu \mathrm{M}$ ) significantly decreased gene expression of IL-6 in LPS-treated cells, while apigenin-trimethylether in the same concentration did not influence IL-6 mRNA level. Both apigenin and apigenin-trimethylether reduced IL-8 gene expression significantly. TNF- $\alpha$ mRNA level was decreased by apigenin-trimethylether, which was not influenced by apigenin. Treatment with both flavonoids caused significant reduction in the mRNA level of COX2 , but the anti-inflammatory effect of the methylated analogue was more effective than the unmethylated one. Furthermore, both flavonoids reduced significantly the level of extracellular $\mathrm{H}_{2} \mathrm{O}_{2}$ compared to the control cells. In conclusion, the methylated apigenin analogue could avoid LPS-induced intestinal inflammation and it could be applied in the future as an effective anti-inflammatory compound.
\end{abstract}

\section{Introduction}

Flavonoids are naturally occurring polyphenolic compounds which are part of the regular human diet, because of their presence in vegetables, fruits, and beverages such as wine, coffee, and tea. A broad spectrum of beneficial effects (e.g., anticancer, antibacterial, and anti-inflammatory) is attributed to these molecules [1-3]. Many of the positive biological actions of flavonoids have been assigned to their antioxidant properties. However, there is an emerging view that flavonoids and their in vivo metabolites do not act only as conventional hydrogen-donating antioxidants but could modulate protein kinase signalling pathways in cells, influencing transcription factor nuclear factor kappa B (NF- $\kappa$ B) [2].

Polymethoxylated flavones (PMFs) or polymethoxyflavones are flavones substituted with two or more methoxy groups. They are coming into center of interest more and more due to their documented wide spectrum of biological activity including anti-inflammatory, anticarcinogenic, and antiatherogenic properties [4-7]. Some of the polymethoxylated citrus flavonoids have also demonstrated antiproliferative properties in preliminary studies $[8,9]$. A novel tangeretin derivative, 5-acetyl-6,7,8, ${ }^{\prime}$-tetramethylnortangeretin, inhibited MCF-7 breast cancer cell growth through both caspase-dependent intrinsic apoptosis and caspase-independent apoptosis pathways [10].

The antiproliferative effects of methoxylated versus hydroxylated flavones were directly compared in SCC-9 human oral squamous carcinoma cells [6]. Apigenin-trimethylether was about eight times more potent than apigenin, one of the most studied hydroxyflavones. More recent research data demonstrated that citrus PMFs are directly associated with the inhibition of enzymes involved in the inflammation [1113]. From previous reports, it seemed that flavonoids with 


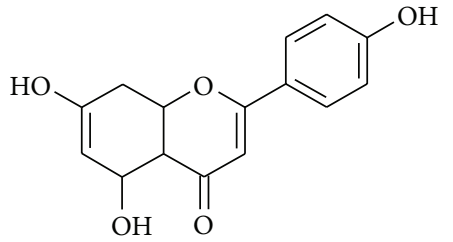

(a)

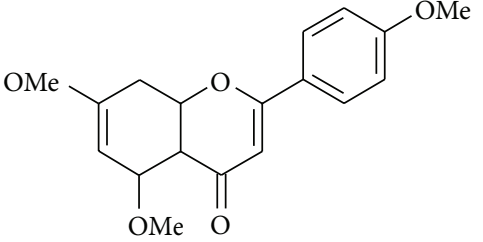

(b)

FIGURE 1: Structure of apigenin $\left(3^{\prime}, 4^{\prime}, 5\right.$-trihydroxyflavone) (a) and apigenin-trimethylether $\left(3^{\prime}, 4^{\prime}, 5\right.$-trimethoxyflavone) (b).

free hydroxyl groups are more physiologically active than their methylated derivatives because of their stronger free radical scavenging activity. Hence, hydroxylated polyphenols scavenge free radical species better, whereas fully methoxylated flavonoids can also effectively inhibit the enzymes like inducible nitric oxide synthase (iNOS) and NADPH oxidase that generate free radicals like $\mathrm{NO}$ and superoxide anion [11, 14]. Nobiletin, the most studied element of the PMF family, has been shown to inhibit the production of prostaglandin E2 (PGE2) in human synovial fibroblasts by selectively downregulating COX-2 $[13,15]$. Gene expression of proinflammatory cytokines, such as IL- $1 \alpha$, IL- $1 \beta$, TNF- $\alpha$, and IL-6, was found downregulated by nobiletin, tangeretin, and $3,5,6,7,8,3^{\prime}, 4^{\prime}$ heptamethoxyflavone $[15,16]$. It has been shown in an LPSinduced mouse macrophage model that nobiletin, tangeretin, and their derivatives moderately attenuated iNOS and COX-2 gene expression $[16,17]$. Nevertheless, the available information about the biological effect of methoxylated flavonoids is not fully explored.

Methoxyflavones originate from plant-derived foods, especially from citrus peel, and could be released from hydroxyflavones by the catechol-O-methyltransferase [18] in the enterocytes. Due to their increased bioavailability [6], methoxylated flavones are more able to induce beneficial effects in vivo as compared to their hydroxylated analogs.

Intestinal epithelial cells play an important role in the innate immune response against pathogenic bacteria. Besides acting as a physical barrier, previous studies suggest that epithelial cells also have significant role in generating signals by the production of several cytokines, chemokines, and other signalling molecules [19-21]. The phosphoglycolipid LPS, component of the outer membrane in Gram-negative bacteria, is recognized by epithelial toll-like receptor-4 (TLR4) [22]. Ligation of TLR initiates a signalling cascade that results in the activation of the transcription factor NF- $\kappa \mathrm{B}$ and subsequent upregulation of costimulatory molecules as well as inflammatory cytokines and chemokines [23]. NF- $\kappa \mathrm{B}$ also regulates the expression of $\mathrm{COX}-2$, affecting the production of prostaglandins.

In vitro gut models offer a suitable alternative to in vivo animal experiments. Cancerous cell lines such as Caco-2 and HT-29 are widely used for this tool. However, the major disadvantage of cell lines originated from cancer tissues is that their glycosylation pattern, proliferation rate, and colonisation ability significantly differ from healthy tissues. The nontransformed porcine intestinal epithelial cell line IPEC$\mathrm{J} 2$, originally isolated from jejunal epithelia of a neonatal unsuckled piglet, models in vivo structure and function of the small intestine more closely than colon tumorigenic cell lines. This cell line forms polarized monolayers with high transepithelial electrical resistance when cultured on $0.4 \mu \mathrm{m}$ pore-size filters, developing apical and basolateral part [24]. Because of the abovementioned facts, IPEC-J2 cell line is a realistic and representative tool for mimicking the human as well as the pig small intestine. It can be good tool for pharmacology research, toxicity, microbiology, bioavailability, and metabolism studies in the field of human as well as veterinary medicine and food science [25].

The main aim of this study is to investigate the possible protective effects of methoxyflavones in intestinal epithelial cells under the condition of inflammation. Apigenin $\left(3^{\prime}, 4^{\prime}\right.$, 5-trihydroxyflavone, Figure 1(a)), a well-studied and abundant flavonoid, and their methylated analogue $\left(3^{\prime}, 4^{\prime}, 5\right.$-trimethoxyflavone, Figure 1(b)) were chosen as test compounds in order to study the abovementioned subject. This is the first report, which describes the effect of apigenin in intestinal inflammation using nontransformed intestinal epithelial cell line. Moreover, comparison of the anti-inflammatory effect of an unmethylated flavonoid and its methylated analogue in a nontransformed intestinal cell model was also performed at first time.

\section{Materials and Methods}

2.1. Chemicals. Apigenin ( $\geq 97 \%)$, dimethyl sulfoxide ( $\geq 99.7 \%$, sterile-filtered, BioReagent), LPS (derived from Salmonella enterica ser. Typhimurium), and $\mathrm{H}_{2} \mathrm{O}_{2}(30 \%)$ were purchased from Sigma-Aldrich (Steinheim, Germany). Apigenin-trimethylether $(\geq 99 \%)$ was from INDOFINE Chemical Company (Hillsborough, NJ, USA).

2.2. Cell Line and Culture Conditions. The nontransformed porcine intestinal epithelial cell line IPEC-J2, originally isolated from jejunal epithelia of a neonatal unsuckled piglet [24], was a kind gift from Dr. Jody Gookin, Department of Clinical Sciences, College of Veterinary Medicine, North Carolina State University, Raleigh, NC, USA. IPEC-J2 cells were grown and maintained in complete medium, which consisted of a 1:1 mixture of Dulbecco's Modified Eagle's Medium and Ham's F-12 Nutrient Mixture (DMEM/F12) (plain medium) supplemented with $5 \%$ foetal bovine serum (FBS), $5 \mu \mathrm{g} / \mathrm{mL}$ insulin, $5 \mu \mathrm{g} / \mathrm{mL}$ transferrin, $5 \mathrm{ng} / \mathrm{mL}$ selenium, $5 \mathrm{ng} / \mathrm{mL}$ epidermal growth factor, and $1 \%$ penicillinstreptomycin (all from Fisher Scientific, Loughborough, UK). 
Cells were grown at $37^{\circ} \mathrm{C}$ in a humidified atmosphere of $5 \%$ $\mathrm{CO}_{2}$. Cell cultures were tested by PCR and they were found to be free of Mycoplasma contamination.

For the experiments, IPEC-J2 cells between passages 42 and 48 were seeded onto six-well Transwell polyester membrane inserts (Corning Inc., Corning, NY, USA), the latter coated with $8 \mu \mathrm{g} / \mathrm{cm}^{2}$ rat tail collagen type I (Sigma-Aldrich, Steinheim, Germany), at a density of $1.5 \times 10^{5}$ cells $/ \mathrm{mL}$ (the volume of complete medium was $1.5 \mathrm{~mL}$ on the apical side and $2.5 \mathrm{~mL}$ on the basolateral side per well according to the manufacturer's instructions). Cells were allowed to adhere for $24 \mathrm{~h}$ before being washed and refed every other day until confluence was reached. Transepithelial electrical resistance (TEER) measurement of monolayers was performed on alternate days after seeding, from days 5 to 21 of culture, using an EVOM Epithelial Tissue Volt/Ohmmeter (World Precision Instruments, Berlin, Germany).

2.3. Neutral Red Uptake Assay for Cell Viability. Influence of apigenin and apigenin-trimethylether on the viability of enterocytes in different concentrations $(25,50$, and $100 \mu \mathrm{M})$ was tested. Flavonoids were dissolved in DMSO and diluted in cell culture medium. The final concentration of DMSO at the cells was $0.1 \%$. In control experiments, this concentration did not show any effects on the measured parameters. IPECJ2 cells were seeded in a 96-well plate and incubated with polyphenols for 1, 2, 4, and $24 \mathrm{~h}$, respectively. Viability of IPEC-J2 cells was measured 24 hours after treatment by Neutral Red uptake assay as described by Repetto et al. [26].

2.4. Treatment of Cells with LPS. Before treatment, confluent monolayers of the IPEC-J2 cells were washed with plain medium. LPS solutions were prepared freshly prior to each experiment. LPS was added in plain medium at $10 \mu \mathrm{g} / \mathrm{mL}$ on the apical side of the IPEC-J2 layer. After $1 \mathrm{~h}$ incubation with LPS and flavones, cells were washed with plain medium and cultured for additional $1 \mathrm{~h}$ for PCR studies. TEER measurements were performed both before and after the LPS treatment.

2.5. Measurement of Extracellular $\mathrm{H}_{2} \mathrm{O}_{2}$. Fluorescent ROS measurement was based on the detection of $\mathrm{H}_{2} \mathrm{O}_{2}$ using the Amplex Red Hydrogen Peroxide Assay Kit (Invitrogen, Molecular Probes) keeping the IPEC-J2 cells on the 96well plate. In the presence of horseradish peroxidase (HRP), Amplex Red reacts with $\mathrm{H}_{2} \mathrm{O}_{2}$ in a 1:1 stoichiometry producing a highly fluorescent resorufin [27].

IPEC-J2 cells were treated with LPS in phenol-red free DMEM and the $\mathrm{H}_{2} \mathrm{O}_{2}$ concentrations in the medium were determined using the working solution of $100 \mu \mathrm{M}$ Amplex Red reagent and $0.2 \mathrm{U} / \mathrm{mL}$ HRP. $\mathrm{H}_{2} \mathrm{O}_{2}$ determination was also performed after $1 \mathrm{~h}$ LPS treatment immediately and $24 \mathrm{~h}$ incubation with phenol-red free DMEM. After $30 \mathrm{~min}$ incubation with the dye at room temperature the quantitative analyses of $\mathrm{H}_{2} \mathrm{O}_{2}$ contents were accomplished, the excitation wavelength was set at $560 \mathrm{~nm}$, and emission was measured at $590 \mathrm{~nm}$ (Victor X2 2030 fluorometer, Perkin Elmer, Waltham, MA, USA).
2.6. Quantitative Real-Time PCR. One hour after the $1 \mathrm{~h}$ LPS treatment, culture medium was removed and $1 \mathrm{~mL}$ of ice-cold TRIzol reagent (Invitrogen, Carlsbad, CA, USA) was added to the IPEC-J2 samples. Samples were collected and kept at $-80^{\circ} \mathrm{C}$ until further processing. Total RNA was isolated from the cells according to the manufacturer's instructions. To prevent DNA contamination, the isolated RNA $(2 \mu \mathrm{g})$ was treated with AMP-D1 DNase I (Sigma). Quantity $A_{260} / A_{280}$ and $A_{260} / A_{230}$ ratios of the extracted RNA were determined using a NanoDrop ND-1000 Spectrophotometer (Thermo Scientific, Wilmington, USA). Quality and quantity control of the isolated RNA were carried out both before and after the DNase treatment.

Synthesis of the first strand of cDNA from $1000 \mathrm{ng}$ of total RNA was achieved using RevertAid H Minus First Strand cDNA Synthesis Kit (Fermentas, St. Leon-Roth, Germany) according to the manufacturer's recommendations, using the random hexamer as a priming method. Quantitative realtime PCR (qRT-PCR) was performed using the iQ SYBR Green Supermix kit (BioRad, Hercules, CA, USA) on the MiniOpticon System (BioRad). The cDNA was diluted 5fold, before equal amounts were added to duplicate qRTPCR reactions. Tested genes of interest were IL-6, IL-8, TNF- $\alpha$, COX-2, and Hsp70. Hypoxanthine phosphoribosyl transferase (HPRT) and Cyclophilin-A (CycA) were used as reference genes. Primer sequences are listed in Table 1. For each PCR reaction, $2.5 \mu \mathrm{L}$ cDNA was added directly to a PCR reaction mixture and set to a final volume of $25 \mu \mathrm{L}$, containing $1 \mathrm{x}$ concentrated iQ SYBR Green Supermix and $0.2 \mu \mathrm{M}$ of the appropriate primers. The thermal profile for all reactions was $3 \mathrm{~min}$ at $95^{\circ} \mathrm{C}$, then 40 cycles of $20 \mathrm{sec}$ at $95^{\circ} \mathrm{C}, 30 \mathrm{sec}$ at $60^{\circ} \mathrm{C}$, and $30 \mathrm{sec}$ at $72^{\circ} \mathrm{C}$. At the end of each cycle, the fluorescence monitoring was set for 10 seconds. Each reaction was completed with a melting curve analysis to ensure the specificity of the reaction. In order to determine the efficiencies of the PCR reactions, standard curves were obtained for each target and reference gene, using serial dilutions of a reference cDNA. Real-time PCR efficiencies $(E)$ were calculated according to the equation: $E=10(-1 /$ slope). To determine the stability of the reference genes, the geNorm (version 3.5) was used.

2.7. Statistics. Relative gene expression levels of the genes of interest were calculated by the Relative Expression Software Tool (REST) 2009 Software (Qiagen GmbH, Hilden, Germany). Statistical analysis of other data was performed with STATISTICA 10 software (StatSoft Inc., Tulsa, USA). Differences between means were evaluated by one-way ANOVA, with data of normal distribution, and homogeneity of variances was confirmed. To compare treated groups to controls we used Dunnett post-hoc test. For the comparison of different treatments we used Fisher LSD test. Level of significance was set at $P<0.05$. All values were expressed as means \pm standard deviations.

\section{Results}

3.1. Viability of IPEC-J2 Cells after Flavonoid Treatment. Viability of IPEC-J2 cells was monitored after apigenin and 
TABLE 1: Sequence of primer sets used for quantitative real-time.

\begin{tabular}{|c|c|c|c|c|c|c|}
\hline $\begin{array}{l}\text { Gene } \\
\text { symbol }\end{array}$ & $\begin{array}{l}\text { Accession } \\
\text { number }\end{array}$ & Primer sequences & Product size (bp) & Efficiency & $R^{2}$ & Reference \\
\hline IL-8 & NM_213867 & $\begin{array}{l}\text { F 5 } 5^{\prime} \text {-AGAGGTCTGCCTGGACCCCA-3' } \\
\text { R } 5^{\prime} \text {-GGGAGCCACGGAGAATGGGT-3' }\end{array}$ & 126 & 1.972 & 0.999 & {$[28]$} \\
\hline IL-6 & NM_214399 & $\begin{array}{l}\text { F 5 } 5^{\prime} \text {-TTCACCTCTCCGGACAAAAC-3' } \\
\text { R 5 '-TCTGCCAGTACCTCCTTGCT-3' }\end{array}$ & 122 & 1.970 & 0.995 & [29] \\
\hline TNF- $\alpha$ & NM_214022 & $\begin{array}{l}\text { F } 5^{\prime} \text {-TTCCAGCTGGCCCCTTGAGC-3' } \\
\text { R 5 }{ }^{\prime} \text {-GAGGGCATTGGCATACCCAC-3' }\end{array}$ & 146 & 1.873 & 0.982 & {$[30]$} \\
\hline $\mathrm{COX}-2$ & NM_214321 & $\begin{array}{l}\text { F 5 } 5^{\prime} \text {-AGAAGCGAGGACCAGCTTTC-3' } \\
\text { R 5'-AAAGCGGAGGTGTTCAGGAG-3' }\end{array}$ & 215 & 1.905 & 0.981 & NCBI/Primer-Blast \\
\hline Hsp70 & NM_001123127 & $\begin{array}{l}\text { F } 5^{\prime} \text {-GCCCTGAATCCGCAGAATA-3' } \\
\text { R } 5^{\prime} \text {-TCCCCACGGTAGGAAACG-3' }\end{array}$ & 152 & 2.0 & 0.993 & {$[31]$} \\
\hline CycA & NM_214353 & $\begin{array}{l}\text { F 5 } 5^{\prime} \text {-GCGTCTCCTTCGAGCTGTT-3' } \\
\text { R 5'-CCATTATGGCGTGTGAAGTC-3' }\end{array}$ & 160 & 1.907 & 0.998 & {$[30]$} \\
\hline HPRT & NM_001032376 & $\begin{array}{l}\text { F } 5^{\prime} \text {-GGACTTGAATCATGTTTGTG-3' } \\
\text { R } 5^{\prime} \text {-CAGATGTTTCCAAACTCAAC-3' }\end{array}$ & 91 & 1.963 & 0.997 & {$[32]$} \\
\hline
\end{tabular}

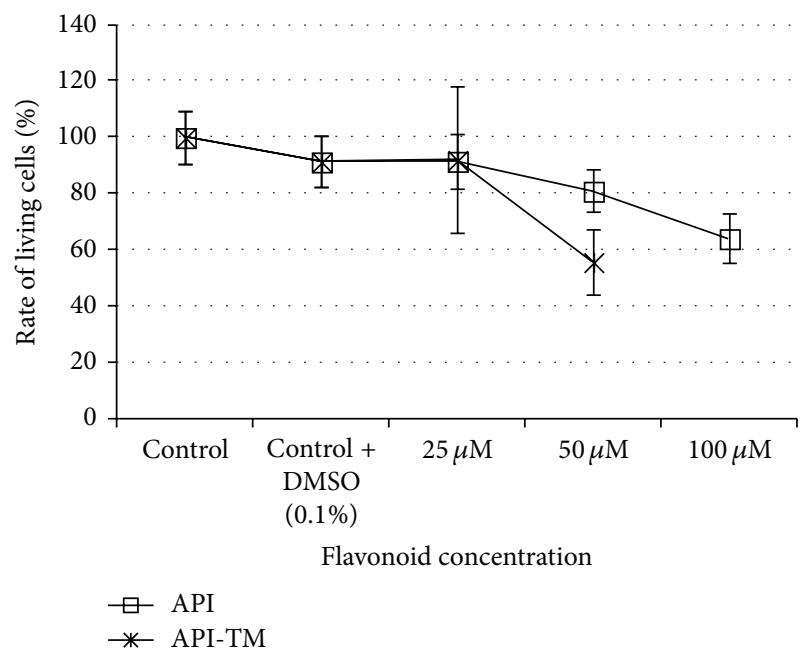

(a)

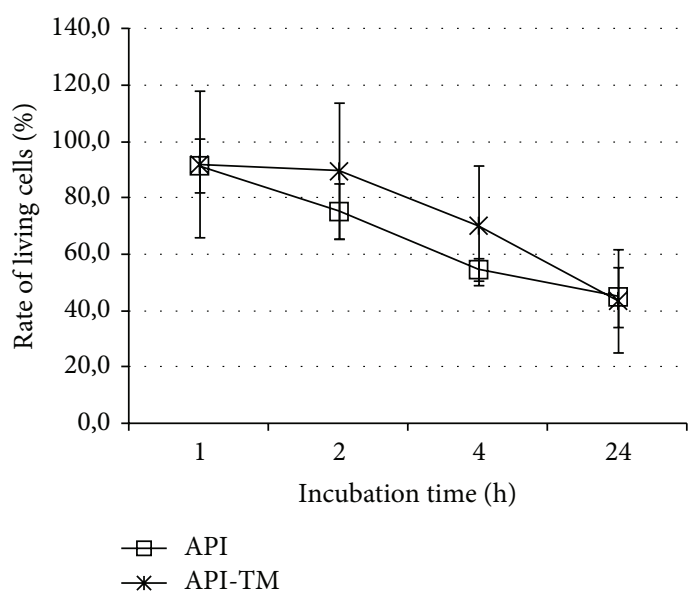

(b)

FIGURE 2: Rate of living IPEC-J2 cells after apigenin and apigenin-trimethylether treatment. Cell viability was tested using Neutral Red uptake method. Effect of flavones on cell viability was studied in a dose- (a) and time-dependent (b) manner. Data are shown as means + standard deviations.

apigenin-trimethyether treatment, respectively (see Figures 2(a) and 2(b)). Neutral Red uptake assay showed that there was no significant difference in number of viable IPEC-J2 cells incubated with plain DMEM containing 0.1\% DMSO. At $25 \mu \mathrm{M}$ treatment dose in case of both flavones for $1 \mathrm{~h}$ did not reduce the number of viable enterocytes significantly. More than $44 \%$ of the IPEC-J2 cells were killed by $1 \mathrm{~h}$ treatment when apigenin-trimethylether was applied at $50 \mu \mathrm{M}$ concentrations, while incubation with $100 \mu \mathrm{M}$ destroyed $55.9 \pm$ $8.53 \%$ of cells. After $1 \mathrm{~h}$ exposure of $50 \mu \mathrm{M}$ and $100 \mu \mathrm{M}$ apigenin, reduced viability of IPEC-J2 cells was detected (rate of living cells decreased to $80.9 \pm 7.49 \%$ and $64.1 \pm 8.53 \%$, resp., compared to the control samples). On the basis of the abovementioned data, it seemed to be safe to use both flavones in $25 \mu \mathrm{M}$ concentration for further experiments. Viability was tested also on a time-dependent manner, using $25 \mu \mathrm{M}$ concentrations of polyphenols. Living cell rate decreased to $75.3 \pm 9.9 \%$ after $2 \mathrm{~h}$ apigenin-trimethylether exposure, while $4 \mathrm{~h}$ and $24 \mathrm{~h}$ treatment greatly reduced number of living IPEC-J2 cells (rate of viable cells was $70.3 \pm 20.1$ and $43.6 \pm 18.3$, resp.). Reduced viability was observed when enterocytes were treated with $25 \mu \mathrm{M}$ apigenin for $4 \mathrm{~h}$ and $24 \mathrm{~h}$, respectively (in preliminary studies rate of viable cells was $54.7 \pm 3.84$ and $45.0 \pm 10.5$, resp.). Therefore, $1 \mathrm{~h}$ treatment period was used in further experiments.

3.2. Inflammatory Response in IPEC-J2 Cells after LPS Treatment. In order to verify the integrity of the IPEC-J2 cell layer, TEER values between apical and basolateral compartment were measured. Experiments were performed with confluent 


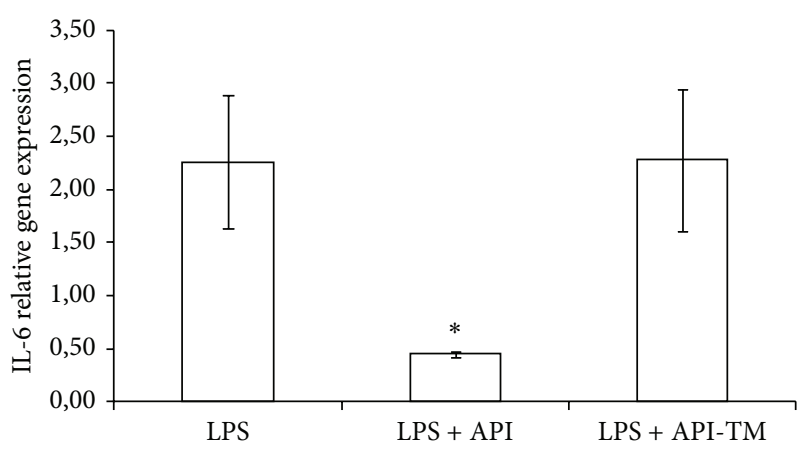

FIGURE 3: Relative gene expression of IL-6 in IPEC-J2 cells exposed to LPS treatment (at $1 \mu \mathrm{g} / \mathrm{mL} ; 1 \mathrm{~h}$ treatment). Effect of apigenin $(25 \mu \mathrm{M})$ and apigenin-trimethylether $(25 \mu \mathrm{M})$ on the IL-6 mRNA levels $\left(n=3-4\right.$ /group; $\left.{ }^{*} P<0.05\right)$. Data are shown as means + standard deviations. API $=$ apigenin; API-TM $=$ apigenin-trimethylether.

polarized IPEC-J2 cells with high TEER values. The integrity of the cell monolayer was not altered after LPS treatment (data not shown).

Relative gene expressions of IL-6, IL-8, TNF- $\alpha$, COX-2, and Hsp70 in LPS-triggered IPEC-J2 cells were determined. LPS treatment significantly increased TNF- $\alpha(P=0.018)$, IL-6 $(P=0.044)$, and IL-8 $(P=0.001)$ relative gene expression levels. Significant upregulation of COX-2 gene was also observed after $1 \mathrm{~h} 10 \mu \mathrm{g} / \mathrm{mL}$ LPS administration $(P=$ $0.012)$. There was no alteration in the mRNA level of heat shock protein $70(P=0.375)$ after LPS treatment.

3.3. Effect of Apigenin and Apigenin-Trimethylether on the Relative Gene Expression of Cytokines TNF- $\alpha, I L-6$, and IL8 in LPS-Treated Enterocytes. At $25 \mu \mathrm{M}$ apigenin treatment dose, relative gene expression of IL-6 significantly decreased compared to LPS-treated cells $(P=0.0348)$. Apigenintrimethylether in the same concentration did not influence the IL-6 mRNA level. Both apigenin $(P=0.0009)$ and apigenin-trimethylether $(P=0.0014)$ caused significant reduction in the IL- 8 gene expression. There was no significant difference in the IL- 8 gene expression reducing effect of apigenin and its unmethylated analogue. TNF- $\alpha$ mRNA level was decreased by $25 \mu \mathrm{M}$ apigenin-trimethylether treatment $(P=0.0081)$, while apigenin did not suppress TNF- $\alpha$ mRNA level compared to the LPS-treated enterocytes. Figures 3-5 show the effect of flavonoids on proinflammatory cytokine gene expressions.

3.4. Cox-2 Relative Gene Expression. Apigenin and apigenintrimethylether treatment caused significant reduction in the mRNA level of COX-2 $(P=0.0287, P=0.0006)$ Effect of apigenin and apigenin-trimethylether was compared using one-way ANOVA (Fisher LSD test). It was shown that there is a significant difference between the effect of hydroxy and methoxy-analogue $(P=0.0264)$. The influence of apigenin and its trimethylated derivative on $\mathrm{COX}-2$ relative gene expression could be seen in Figure 6.

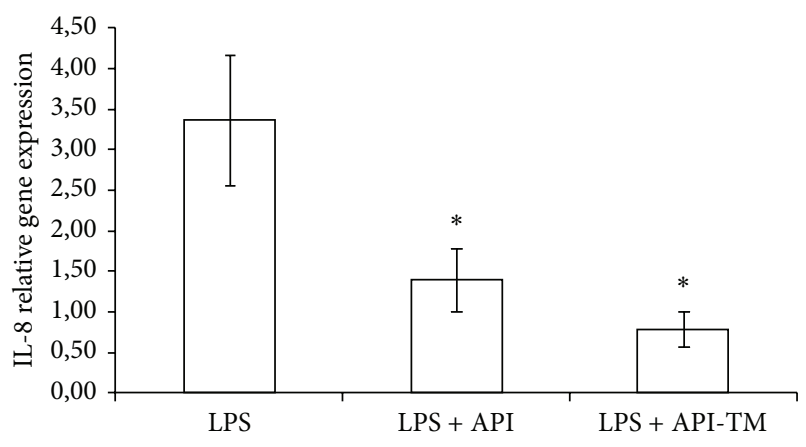

FIgURE 4: Relative gene expression of IL-8 in IPEC-J2 cells exposed to LPS treatment (at $1 \mu \mathrm{g} / \mathrm{mL} ; 1 \mathrm{~h}$ treatment). Effect of apigenin $(25 \mu \mathrm{M})$ and apigenin-trimethylether $(25 \mu \mathrm{M})$ on the IL-8 mRNA levels $\left(n=3-4 /\right.$ group; $\left.{ }^{*} P<0.05\right)$. Data are shown as means + standard deviations. API = apigenin; API-TM = apigenin-trimethylether.

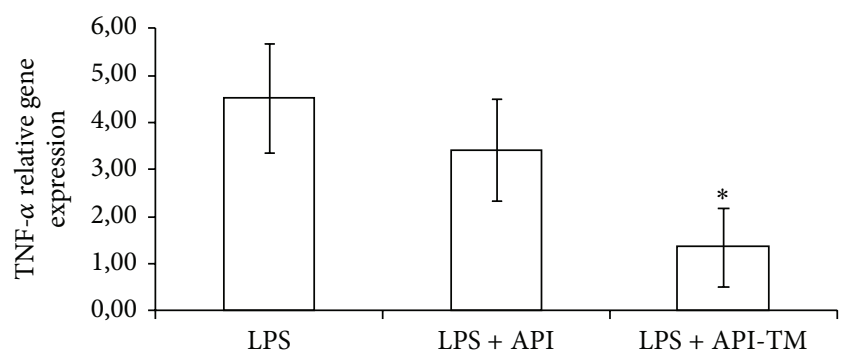

FIgURE 5: Relative gene expression of TNF- $\alpha$ in IPEC-J2 cells exposed to LPS treatment (at $1 \mu \mathrm{g} / \mathrm{mL} ; 1 \mathrm{~h}$ treatment). Effect of apigenin $(25 \mu \mathrm{M})$ and apigenin-trimethylether $(25 \mu \mathrm{M})$ on the TNF$\alpha$ mRNA levels $\left(n=3-4 /\right.$ group; $\left.{ }^{*} P<0.05\right)$. Data are shown as means + standard deviations. API $=$ apigenin; API-TM $=$ apigenintrimethylether.

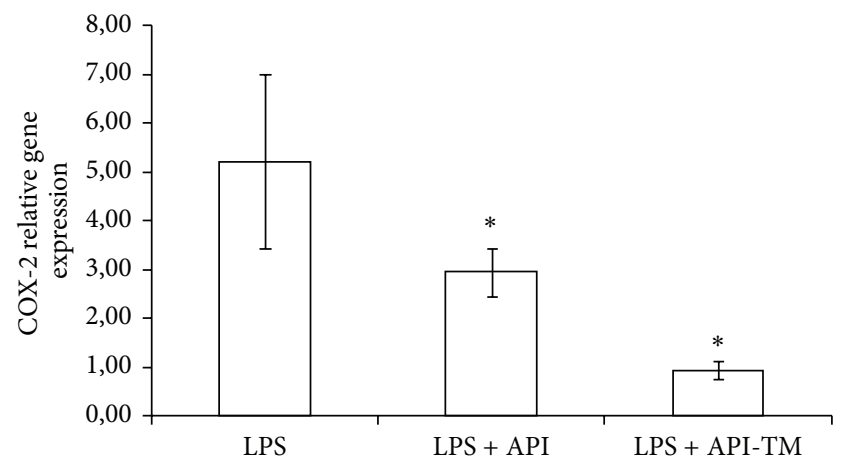

FIgURE 6: Relative gene expression of COX-2 in IPEC-J2 cells exposed to LPS treatment (at $1 \mu \mathrm{g} / \mathrm{mL} ; 1 \mathrm{~h}$ treatment). Effect of apigenin $(25 \mu \mathrm{M})$ and apigenin-trimethylether $(25 \mu \mathrm{M})$ on the COX-2 mRNA levels $\left(n=3-4 /\right.$ group; $\left.{ }^{*} P<0.05\right)$. Data are shown as means + standard deviations. API = apigenin; API-TM $=$ apigenintrimethylether. 


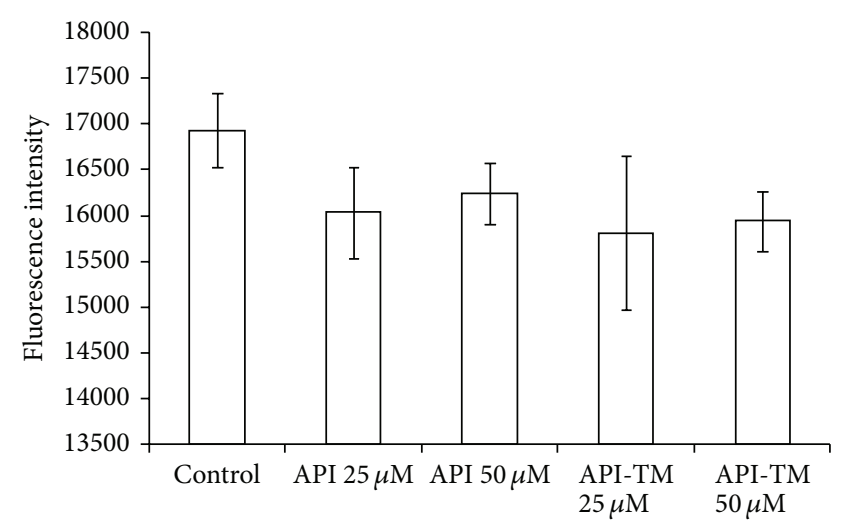

(a)

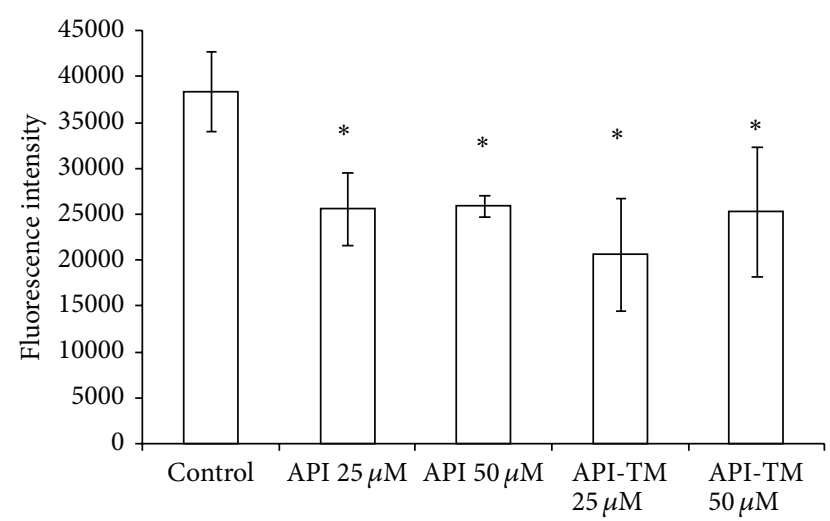

(b)

Figure 7: Level of extracellular $\mathrm{H}_{2} \mathrm{O}_{2}$ in IPEC-J2 cells exposed to flavonoid treatment (25 and $\left.50 \mu \mathrm{M} ; 1 \mathrm{~h}\right)$. Effect of apigenin and apigenintrimethylether on the relative extracellular $\mathrm{H}_{2} \mathrm{O}_{2}$ levels $\left(n=3-4\right.$ /group; $\left.{ }^{*} \mathrm{P}<0.05\right)$. Fluorescence measurement was performed by Amplex Red method. Fluorescence was detected immediately (a) and $24 \mathrm{~h}$ after (b) flavonoid treatment. Data are shown as means + standard deviations. API = apigenin; API-TM = apigenin-trimethylether.

3.5. Extracellular $\mathrm{H}_{2} \mathrm{O}_{2}$ Production in IPEC-J2 Cells after LPS and Flavonoid Treatment. Figure 7 shows the relative extracellular $\mathrm{H}_{2} \mathrm{O}_{2}$ level in IPEC-J2 cells after flavonoid treatment. LPS only at higher concentration (at $50 \mu \mathrm{g} / \mathrm{mL}$ ) increased the level of extracellular $\mathrm{H}_{2} \mathrm{O}_{2}$; however, IPEC-J2 cells are irreversibly damaged using LPS in this concentration (data not shown). Flavonoids showed different effects on the rate of $\mathrm{H}_{2} \mathrm{O}_{2}$ production, depending on the duration of incubation in DMEM after flavonoid treatment. In case of short time effect measurements $(1 \mathrm{~h}$ incubation with flavonoids and detection immediately after the incubation period), neither apigenin nor its trimethylated analogue decreased mitochondrial $\mathrm{H}_{2} \mathrm{O}_{2}$ production rate effectively. Long time effects of flavonoid treatment (Amplex Red measurement was performed $24 \mathrm{~h}$ after the $1 \mathrm{~h}$ flavonoid incubation) were also studied. Extracellular $\mathrm{H}_{2} \mathrm{O}_{2}$ level was significantly decreased in case of both lower $(25 \mu \mathrm{M})$ and higher $(50 \mu \mathrm{M})$ concentration apigenin treatments. The same reducing effect was found, when $25 \mu \mathrm{M}$ and $50 \mu \mathrm{M}$ apigenin-trimethylether were applied.

\section{Discussion}

LPS, a major integral component of the outer membrane of Gram-negative bacteria, is widely used to induce inflammation in case of several cell types, including small intestinal cell lines such as IPEC-J2. NF- $\kappa \mathrm{B}$ activation resulted in the expression of a wide range of genes, many of which are markedly upregulated in response to microbial infection and inflammation. Some of these are cytokines and chemokines (IL-1, IL-6, IL-8, and TNF- $\alpha$ ) and inflammatory enzymes such as COX-2. The inhibition of signal transduction pathways at any point of the inflammatory cascade reduces the production of these proteins, which modulates the inflammation locally [33].

Considering the literature $[21,34,35]$ and our previous results, detection of relative gene expression of proinflammatory cytokines in IPEC-J2 intestinal epithelial cells was optimal after 1 and 2 hours [36, 37]. In our experiments, $1 \mathrm{~h}$ incubation of IPEC-J2 cells with LPS (and further $1 \mathrm{~h}$ incubation with medium) resulted in significantly high relative IL-6, IL-8, and TNF- $\alpha$ as well as COX-2 gene expression level. Relative expression of the abovementioned genes was tested $4 \mathrm{~h}$ after LPS treatment as well, and those results did not differ significantly from the expression data from $1 \mathrm{~h}$ LPS treatment. Expression of TLR-4, a key element of the activation of NF- $\kappa$ B, in IPEC-J2 cells after LPS treatment was also measured in our previous study [37]. No difference in the TLR-4 expression was detected compared to the control samples, using different concentrations, incubation times, and different types of LPS. Our data agrees with the results of other studies [23,38,39], that epithelial cell lines often show a low level expression of TLR-4, explained by the fact that intestinal epithelial cells are relative resistant to the permanent exposure to Gram-negative commensal bacteria.

The in vitro anti-inflammatory effect of apigenin was studied in many cases. However, these reports were performed using cancerous cell lines or immune cells. LPSstimulated human peripheral blood mononuclear cells were cultured in the presence of apigenin, and TNF- $\alpha$, IL- $1 \beta$, and IL-6 were measured in the cell culture supernatant [40]. Apigenin inhibited proinflammatory cytokine production dose-dependently. Murine macrophage cells and mice were treated with LPS and herbal constituents by Smolinski and Pestka [41]. IL-6 and TNF- $\alpha$ were measured from serum and supernatant by ELISA. All three constituents including apigenin inhibited LPS-induced IL- 6 and TNF- $\alpha$ production in murine macrophage culture. Inhibition of these two cytokines in mice did not display the same patterns of inhibition as cell culture data. In vitro cotreatment with apigenin reduced LPS-induced IL-6, but not TNF- $\alpha$ production. Cotreatment with 3.7 and $37 \mathrm{mM}$ of apigenin significantly reduced IL-6, while inhibition of TNF- $\alpha$ was not observed. However, a study of Mastuda et al. [42] showed that apigenin, at IC50 $=5.3 \mathrm{mM}$, inhibited antigen-IgE-mediated TNF- $\alpha$ secretion in RBL-2H3 mast cells. Apigenin also inhibited 
TNF- $\alpha$ production as well as iNOS expression and NO production in LPS-activated macrophages, and this effect has been associated with the inhibition of the NF- $\kappa \mathrm{B}$ pathway [43]. Apigenin inhibited TNF- $\alpha$ secretion in a concentrationdependent manner. It shows only a slight effect on TNF$\alpha$ release that did not reach $25 \mu \mathrm{M}$ concentration, whereas apigenin decreases TNF- $\alpha$ release by $41.6 \%$ at $50 \mu \mathrm{M}$. In our model, apigenin $(25 \mu \mathrm{M})$ treatment reduced both IL- 6 and IL-8 mRNA level significantly compared to the LPS-treated group, while it did not affect TNF- $\alpha$. A potential reason for the differences in results could be the differences in stimuli and cell types used.

In a study of Wang and Huang [44] the anti-inflammatory effects of apigenin in Helicobacter pylori-infected human stomach adenocarcinoma cells (MKN45) were investigated and expression of $\mathrm{I}-\kappa \mathrm{B}-\mathrm{a}, \mathrm{COX}-2$, and proinflammatory cytokines was measured. Apigenin treatment $(9.3-74 \mu \mathrm{M})$ significantly increased I- $\kappa \mathrm{B}-\mathrm{a}$ expression and thus inhibited NF- $\kappa$ B activation. Expression of IL-8, IL-6, and COX-2 was significantly decreased. Apigenin inhibited the production of NO and PGE2 by suppressing the expression of iNOS and COX-2 protein in murine microglia cell line model [45]. Moreover, it suppressed p38 mitogen-activated protein kinase and c-Jun $\mathrm{N}$-terminal kinase (JNK) phosphorylation without affecting the activity of extracellular signal-regulated kinase (ERK).

In terms of anti-inflammatory effect, only a few studies have reported methoxyflavones. The most studied methoxylated flavones originated from citrus peel. Citrus aurantium L. extract containing nobiletin, naringin, and hesperidin inhibited the proinflammatory mediators including cytokines, COX-2, and iNOS by blocking NF- $\kappa \mathrm{B}$ and mitogen-activated protein kinase (MAPK) signalling in LPSstimulated macrophages. The molecular mechanism was associated with inhibition of the phosphorylation of I- $\kappa \mathrm{B}-$ $a$ and nuclear translocation of the NF- $\kappa \mathrm{B}$ p-65 as well as phosphorylation of MAPK by flavonoids [46]. Contrarily, a formulated product from citrus peel extract (Gold Lotion) inhibited the gene expression of iNOS, but not COX-2 in a mouse skin inflammatory model. These differential effects may be explained due to the degree of dependency of iNOS and COX-2 promoters on various transcription factors [47]. Nobiletin has been shown to significantly suppress the activation of activator protein $1, \mathrm{NF}-\kappa \mathrm{B}$, and cAMP response element-binding protein (CREB) [13].

During and Larondelle [48] studied whether methoxylated flavones versus their unmethylated analogs can modulate the intestinal inflammatory response. After IL- $1 \beta$ stimulus of Caco- 2 cells, the anti-inflammatory activity of apigenin, chrysin, luteolin, and quercetin was investigated. Their results indicate that methoxylation of chrysin improves its antiinflammatory effect significantly, probably through a more explicit inhibition of the NF- $\kappa \mathrm{B}$ signaling pathway. Nevertheless, the abovementioned effect was not observed in case of other flavonoids. Furthermore, neither apigenin nor its methylated analogue reduced IL-8 level significantly, but IL-6 and PGE- 2 concentration were reduced by both compounds.
It seems that hydroxyflavones and their methoxylated analogues share the same signal transduction pathways; however, methoxyflavones needs further investigations.

Oxidative stress is defined as an imbalance between production of free radicals and reactive metabolites, referred to as reactive oxygen species (ROS), and their elimination by protective mechanisms, so-called antioxidants [49]. This loss of equilibrium leads to damage of important biomolecules, with potential impact on the whole organism. Oxidative stress could activate a variety of transcription factors including NF$\kappa \mathrm{B}$ and lead to chronic inflammation. Flavonoid antioxidants could protect cells against the damaging effects of ROS [50].

In this study, some oxidative stress markers were also followed. It was found that neither the mRNA level of Hsp70 nor level of extracellular $\mathrm{H}_{2} \mathrm{O}_{2}$ was affected by $10 \mu \mathrm{g} / \mathrm{mL}$ LPS treatment. LPS in higher concentration $(50 \mu \mathrm{g} / \mathrm{mL})$ increased extracellular $\mathrm{H}_{2} \mathrm{O}_{2}$ level significantly; however, IPEC-J2 cells are irreversibly damaged (data not shown).

Nevertheless, effect of flavones on oxidative stress markers is worthy to be investigated, because they could act not only as antioxidants but also as prooxidants; that is, they are potential inducers of oxidative stress. The prooxidant potential of apigenin was studied by Miyoshi et al. [51]. Flow cytometric measurements and immunoblotting showed the intracellular accumulations of ROS and protein carbonyls in the cells treated with apigenin in a dose-dependent manner. In HL-60 cells treated with $50 \mu \mathrm{M}$ apigenin for $1 \mathrm{~h}$, ROS level was 3.5-fold increased compared to control cells. Structure-activity relationship data suggested that presence of 4-hydroxy group and also the absence of 3-and 3 '-hydroxy groups are important for prooxidant effect. Treatment cells with $25 \mu \mathrm{M}$ apigenin did not affect the extracellular ROS status. On the basis of our measurements in IPEC-2 intestinal epithelial cells, no prooxidant effect was observed. Moreover, extracellular $\mathrm{H}_{2} \mathrm{O}_{2}$ level in IPEC-J2 cells was significantly decreased $24 \mathrm{~h}$ after flavonoid treatment in case of both apigenin and apigenin-trimethylether. Deng et al. [52] compared the cytoprotective effect of methylated polyphenols and their unmethylated analogues. They found that methylation largely reduced chemical antioxidant capacity, but methylated flavons can still effectively protect lymphocytes from hydrogen peroxide-induced cytotoxicity.

The biological fate of the flavonoids is very complex, and it is dependent on a large number of parameters. Different activities could be influenced by the different absorption rate and metabolism. Absorption and metabolism studies of hydroxyflavones and methoxyflavones have been investigated primarily in cancer studies $[6,53]$. Caco- 2 cell model was established to test the absorption as well as permeability of polymethoxyflavones in the human intestine. Three compounds ( $3^{\prime}$-hydroxy-5,6,7,4' ${ }^{\prime}$-tetramethoxyflavone, $3,5,6$, $7,8,3^{\prime}, 4^{\prime}$-heptamethoxyflavone, and 3-hydroxy-5,6,7,8,3 $3^{\prime}, 4^{\prime}$ hexamethoxyflavone) showed very high permeability [54, 55]. The membrane transporters as well as metabolic enzymes could influence the cellular availability of polyphenols, affecting their anticancer potential. Nevertheless, absorptive and metabolism properties of these compounds could influence their anti-inflammation activities in the same way. 
In conclusion, methylated flavonoids including apigenintrimethylether may be useful tools in the treatment of intestinal inflammations in human as well in veterinary medicine. Future perspectives should include understanding the molecular basis for inhibitory effects of these compounds on proinflammatory cytokine gene expression and the role of altered absorption and metabolism.

\section{Abbreviations}

LPS: Lipopolysaccharide

IL-6: Interleukin-6

IL-8: Interleukin-8

TNF- $\alpha$ : Tumor necrosis factor alpha

COX-2: Cyclooxygenase 2.

\section{Conflict of Interests}

The authors declare that there is no conflict of interests regarding the publication of this paper.

\section{Acknowledgments}

The research described here was supported by the Hungarian Scientific Research Fund (OTKA 105718) and by the Research Faculty Grant 2014 of the Szent István University, Faculty of Veterinary Science. The authors are indebted to Dr. Jody Gookin (Department of Clinical Sciences, College of Veterinary Medicine, North Carolina State University, Raleigh, NC, USA) for providing the IPEC-J2 cells.

\section{References}

[1] K. Bisht, K.-H. Wagner, and A. C. Bulmer, "Curcumin, resveratrol and flavonoids as anti-inflammatory, cyto- and DNAprotective dietary compounds," Toxicology, vol. 278, no. 1, pp. 88-100, 2010.

[2] R. J. Williams, J. P. E. Spencer, and C. Rice-Evans, "Flavonoids: antioxidants or signalling molecules?" Free Radical Biology and Medicine, vol. 36, no. 7, pp. 838-849, 2004.

[3] B. H. Havsteen, "The biochemistry and medical significance of the flavonoids," Pharmacology and Therapeutics, vol. 96, no. 2-3, pp. 67-202, 2002.

[4] A. Murakami, Y. Nakamura, K. Torikai et al., "Inhibitory effect of citrus nobiletin on phorbol ester-induced skin inflammation, oxidative stress, and tumor promotion mice," Cancer Research, vol. 60 , no. 18 , pp. 5059-5066, 2000.

[5] S. Li, C. Y. Lo, and C. T. Ho, "Hydroxylated polymethoxyflavones and methylated flavonoids in sweet orange (Citrus sinensis) peel," Journal of Agricultural and Food Chemistry, vol. 54, no. 12, pp. 4176-4185, 2006.

[6] T. Walle, N. Ta, T. Kawamori, X. Wen, P. A. Tsuji, and U. K. Walle, "Cancer chemopreventive properties of orally bioavailable flavonoids-methylated versus unmethylated flavones," Biochemical Pharmacology, vol. 73, no. 9, pp. 1288-1296, 2007.

[7] U. K. Walle and T. Walle, "Bioavailable flavonoids: cytochrome P450-mediated metabolism of methoxyflavones," Drug Metabolism and Disposition, vol. 35, no. 11, pp. 1985-1989, 2007.
[8] J. A. Manthey, K. Grohmann, and N. Guthrie, "Biological properties of citrus flavonoids pertaining to cancer and inflammation," Current Medicinal Chemistry, vol. 8, no. 2, pp. 135-153, 2001.

[9] J. A. Manthey and N. Guthrie, "Antiproliferative activities of citrus flavonoids against six human cancer cell lines," Journal of Agricultural and Food Chemistry, vol. 50, no. 21, pp. 5837-5843, 2002.

[10] J. Wang, Y. Duan, D. Zhi et al., "Pro-apoptotic effects of the novel tangeretin derivate 5-acetyl-6,7,8,4'-tetramethylnortangeretin on MCF-7 breast cancer cells," Cell Biochemistry and Biophysics, vol. 70, no. 2, pp. 1255-1263, 2014.

[11] S.-Y. Choi, H.-C. Ko, S.-Y. Ko et al., "Correlation between flavonoid content and the NO production inhibitory activity of peel extracts from various citrus fruits," Biological and Pharmaceutical Bulletin, vol. 30, no. 4, pp. 772-778, 2007.

[12] A. Murakami, S. Kuwahara, Y. Takahashi et al., "In vitro absorption and metabolism of nobiletin, a chemopreventive polymethoxyflavonoid in citrus fruits," Bioscience, Biotechnology and Biochemistry, vol. 65, no. 1, pp. 194-197, 2001.

[13] A. Murakami, T. Shigemori, and H. Ohigashi, "Zingiberaceous and citrus constituents, $1^{\prime}$-acetoxychavicol acetate, zerumbone, auraptene, and nobiletin, suppress lipopolysaccharide-induced cyclooxygenase-2 expression in RAW264.7 murine macrophages through different modes of action," Journal of Nutrition, vol. 135, no. 12, supplement, pp. 2987S-2992S, 2005.

[14] A. Murakami, Y. Nakamura, Y. Ohto et al., "Suppressive effects of citrus fruits on free radical generation and nobiletin, an antiinflammatory polymethoxyflavonoid," BioFactors, vol. 12, no. 14, pp. 187-192, 2000.

[15] N. Lin, T. Sato, Y. Takayama et al., "Novel anti-inflammatory actions of nobiletin, a citrus polymethoxy flavonoid, on human synovial fibroblasts and mouse macrophages," Biochemical Pharmacology, vol. 65, no. 12, pp. 2065-2071, 2003.

[16] J. A. Manthey, K. Grohmann, A. Montanari, K. Ash, and C. L. Manthey, "Polymethoxylated flavones derived from citrus suppress tumor necrosis factor-alpha expression by human monocytes," Journal of Natural Products, vol. 62, no. 3, pp. 441444, 1999.

[17] S. Li, S. Sang, M.-H. Pan et al., "Anti-inflammatory property of the urinary metabolites of nobiletin in mouse," Bioorganic and Medicinal Chemistry Letters, vol. 17, no. 18, pp. 5177-5181, 2007.

[18] H. Lu, X. Meng, and C. S. Yang, "Enzymology of methylation of tea catechins and inhibition of catechol-O-methyltransferase by (-)-epigallocatechin gallate," Drug Metabolism and Disposition, vol. 31, no. 5, pp. 572-579, 2003.

[19] F. Bäckhed, S. Normark, E. K. H. Schweda, S. Oscarson, and A. Richter-Dahlfors, "Structural requirements for TLR4-mediated LPS signalling: a biological role for LPS modifications," Microbes and Infection, vol. 5, no. 12, pp. 1057-1063, 2003.

[20] R. S. Pitman and R. S. Blumberg, "First line of defense: the role of the intestinal epithelium as an active component of the mucosal immune system," Journal of Gastroenterology, vol. 35, no. 11, pp. 805-814, 2000.

[21] C. Arce, M. Ramírez-Boo, C. Lucena, and J. J. Garrido, "Innate immune activation of swine intestinal epithelial cell lines (IPEC-J2 and IPI-2I) in response to LPS from Salmonella typhimurium," Comparative Immunology, Microbiology and Infectious Diseases, vol. 33, no. 2, pp. 161-174, 2010. 
[22] M. T. Abreu, "Toll-like receptor signalling in the intestinal epithelium: how bacterial recognition shapes intestinal function," Nature Reviews Immunology, vol. 10, no. 2, pp. 131-143, 2010.

[23] T. E. Burkey, K. A. Skjolaas, S. S. Dritz, and J. E. Minton, "Expression of Toll-like receptors, interleukin 8, macrophage migration inhibitory factor, and osteopontin in tissues from pigs challenged with Salmonella enterica serovar Typhimurium or serovar Choleraesuis," Veterinary Immunology and Immunopathology, vol. 115, no. 3-4, pp. 309-319, 2007.

[24] P. Schierack, M. Nordhoff, M. Pollmann et al., "Characterization of a porcine intestinal epithelial cell line for in vitro studies of microbial pathogenesis in swine," Histochemistry and Cell Biology, vol. 125, no. 3, pp. 293-305, 2006.

[25] T. Langerholc, P. A. Maragkoudakis, J. Wollgast, L. Gradisnik, and A. Cencic, "Novel and established intestinal cell line models-an indispensable tool in food science and nutrition," Trends in Food Science and Technology, vol. 22, no. 1, pp. S11S20, 2011.

[26] G. Repetto, A. del Peso, and J. L. Zurita, "Neutral red uptake assay for the estimation of cell viability/cytotoxicity," Nature Protocols, vol. 3, no. 7, pp. 1125-1131, 2008.

[27] J. G. Mohanty, J. S. Jaffe, E. S. Schulman, and D. G. Raible, "A highly sensitive fluorescent micro-assay of $\mathrm{H}_{2} \mathrm{O}_{2}$ release from activated human leukocytes using a dihydroxyphenoxazine derivative," Journal of Immunological Methods, vol. 202, no. 2, pp. 133-141, 1997.

[28] E. Paszti-Gere, E. Csibrik-Nemeth, K. Szeker, R. Csizinszky, C. Jakab, and P. Galfi, "Acute oxidative stress affects IL-8 and TNF-alpha expression in IPEC-J2 porcine epithelial cells," Inflammation, vol. 35, no. 3, pp. 994-1004, 2012.

[29] R. Sakumoto, T. Komatsu, E. Kasuya, T. Saito, and K. Okuda, "Expression of mRNAs for interleukin-4, interleukin-6 and their receptors in porcine corpus luteum during the estrous cycle," Domestic Animal Endocrinology, vol. 31, no. 3, pp. 246257, 2006.

[30] K. A. Hyland, D. R. Brown, and M. P. Murtaugh, "Salmonella enterica serovar Choleraesuis infection of the porcine jejunal Peyer's patch rapidly induces IL-1 $\beta$ and IL-8 expression," Veterinary Immunology and Immunopathology, vol. 109, no. 1-2, pp. 1-11, 2006.

[31] X. Zhong, T. Wang, X. Zhang, and W. Li, "Heat shock protein 70 is upregulated in the intestine of intrauterine growth retardation piglets," Cell Stress and Chaperones, vol. 15, no. 3, pp. 335-342, 2010.

[32] A.-B. Nygard, C. B. Jørgensen, S. Cirera, and M. Fredholm, "Selection of reference genes for gene expression studies in pig tissues using SYBR green qPCR,” BMC Molecular Biology, vol. 8, article 67, 2007.

[33] J. J. Malago, J. F. J. G. Koninkx, and J. E. van Dijk, "The heat shock response and cytoprotection of the intestinal epithelium," Cell Stress \& Chaperones, vol. 7, no. 2, pp. 191-199, 2002.

[34] M. M. Geens and T. A. Niewold, "Preliminary characterization of the transcriptional response of the porcine intestinal cell line IPEC-J2 to enterotoxigenic Escherichia coli, Escherichia coli, and E. coli lipopolysaccharide," Comparative and Functional Genomics, vol. 2010, Article ID 469583, 11 pages, 2010.

[35] T. Angrisano, R. Pero, S. Peluso et al., "LPS-induced IL-8 activation in human intestinal epithelial cells is accompanied by specific histone $\mathrm{H} 3$ acetylation and methylation changes," $B M C$ Microbiology, vol. 10, article 172, 2010.
[36] E. Paszti-Gere, G. Matis, O. Farkas et al., "The effects of intestinal LPS exposure on inflammatory responses in a porcine enterohepatic co-culture system," Inflammation, vol. 37, no. 1, pp. 247-260, 2014.

[37] O. Farkas, G. Matis, E. Paszti-Gere et al., "Effects of Lactobacillus plantarum 2142 and sodium n-butyrate in lipopolysaccharidetriggered inflammation: comparison of a porcine intestinal epithelial cell line and primary hepatocyte monocultures with a porcine enterohepatic co-culture system," Journal of Animal Science, vol. 92, no. 9, pp. 3835-3845, 2014.

[38] M. T. Abreu, P. Vora, E. Faure, L. S. Thomas, E. T. Arnold, and M. Arditi, "Decreased expression of Toll-like receptor-4 and MD-2 correlates with intestinal epithelial cell protection against dysregulated proinflammatory gene expression in response to bacterial lipopolysaccharide," Journal of Immunology, vol. 167, no. 3, pp. 1609-1616, 2001.

[39] J. Alvarado, P. Taylor, J. R. del Castillo, and L. E. Thomas, "Interferon gamma bound to extracellular matrix changes the hyporesponsiveness to LPS in crypt but not villous intestinal epithelial cells," Immunology Letters, vol. 99, no. 1, pp. 109-112, 2005.

[40] S. Hougee, A. Sanders, J. Faber et al., "Decreased proinflammatory cytokine production by LPS-stimulated PBMC upon in vitro incubation with the flavonoids apigenin, luteolin or chrysin, due to selective elimination of monocytes/macrophages," Biochemical Pharmacology, vol. 69, no. 2, pp. 241-248, 2005.

[41] A. T. Smolinski and J. J. Pestka, "Modulation of lipopolysaccharide-induced proinflammatory cytokine production in vitro and in vivo by the herbal constituents apigenin (chamomile), ginsenoside Rb1 (ginseng) and parthenolide (feverfew)," Food and Chemical Toxicology, vol. 41, no. 10, pp. 1381-1390, 2003.

[42] H. Mastuda, T. Morikawa, K. Ueda, H. Managi, and M. Yoshikawa, "Structural requirements of flavonoids for inhibition of antigen-induced degranulation, TNF- $\alpha$ and IL- 4 production from RBL-2H3 cells," Bioorganic \& Medicinal Chemistry, vol. 10, no. 10, pp. 3123-3128, 2002.

[43] M. Comalada, I. Ballester, E. Bailón et al., "Inhibition of proinflammatory markers in primary bone marrow-derived mouse macrophages by naturally occurring flavonoids: analysis of the structure-activity relationship," Biochemical Pharmacology, vol. 72, no. 8, pp. 1010-1021, 2006.

[44] Y.-C. Wang and K.-M. Huang, "In vitro anti-inflammatory effect of apigenin in the Helicobacter pylori-infected gastric adenocarcinoma cells," Food and Chemical Toxicology, vol. 53, pp. 376-383, 2013.

[45] S. K. Ha, P. Lee, J. A. Park et al., "Apigenin inhibits the production of $\mathrm{NO}$ and $\mathrm{PGE}_{2}$ in microglia and inhibits neuronal cell death in a middle cerebral artery occlusion-induced focal ischemia mice model," Neurochemistry International, vol. 52, no. 4-5, pp. 878-886, 2008.

[46] S. R. Kang, K. I. Park, H. S. Park et al., "Anti-inflammatory effect of flavonoids isolated from Korea Citrus aurantium L. on lipopolysaccharide-induced mouse macrophage RAW 264.7 cells by blocking of nuclear factor-kappa B (NF- $\kappa$ B) and mitogen-activated protein kinase (MAPK) signalling pathways," Food Chemistry, vol. 129, no. 4, pp. 1721-1728, 2011.

[47] M.-H. Pan, S. Li, C.-S. Lai, Y. Miyauchi, M. Suzawa, and C.T. Ho, "Inhibition of citrus flavonoids on 12-O-tetradecanoylphorbol 13-acetate-induced skin inflammation and tumorigenesis in mice," Food Science and Human Wellness, vol. 1, no. 1, pp. 65-73, 2012. 
[48] A. During and Y. Larondelle, "The O-methylation of chrysin markedly improves its intestinal anti-inflammatory properties: structure-activity relationships of flavones," Biochemical Pharmacology, vol. 86, no. 12, pp. 1739-1746, 2013.

[49] S. Reuter, S. C. Gupta, M. M. Chaturvedi, and B. B. Aggarwal, "Oxidative stress, inflammation, and cancer: how are they linked?” Free Radical Biology and Medicine, vol. 49, no. 11, pp. 1603-1616, 2010.

[50] C. Rice-Evans, "Flavonoid antioxidants," Current Medicinal Chemistry, vol. 8, no. 7, pp. 797-807, 2001.

[51] N. Miyoshi, K. Naniwa, T. Yamada, T. Osawa, and Y. Nakamura, "Dietary flavonoid apigenin is a potential inducer of intracellular oxidative stress: the role in the interruptive apoptotic signal," Archives of Biochemistry and Biophysics, vol. 466, no. 2, pp. 274282, 2007.

[52] D. W. Deng, J. L. Zhang, J. M. Cooney et al., "Methylated polyphenols are poor 'chemical' antioxidants but can still effectively protect cells from hydrogen peroxide-induced cytotoxicity," FEBS Letters, vol. 580, no. 22, pp. 5247-5250, 2006.

[53] T. Walle, "Absorption and metabolism of flavonoids," Free Radical Biology and Medicine, vol. 36, no. 7, pp. 829-837, 2004.

[54] L. Wang, J. Wang, L. Fang et al., "Anticancer activities of citrus peel polymethoxyflavones related to angiogenesis and others," BioMed Research International, vol. 2014, Article ID 453972, 10 pages, 2014.

[55] S. Li, M.-H. Pan, C.-Y. Lo et al., "Chemistry and health effects of polymethoxyflavones and hydroxylated polymethoxyflavones," Journal of Functional Foods, vol. 1, no. 1, pp. 2-12, 2009. 


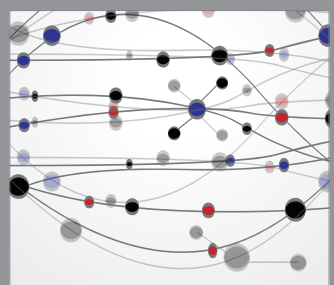

The Scientific World Journal
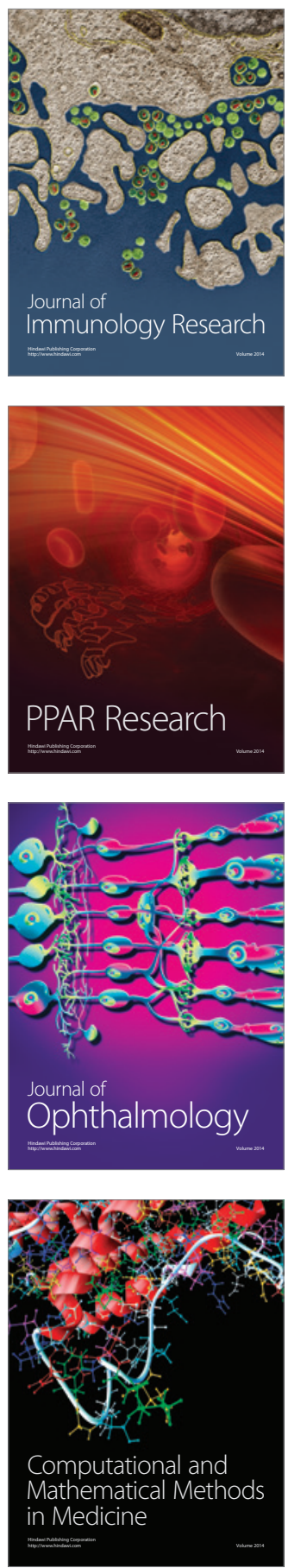

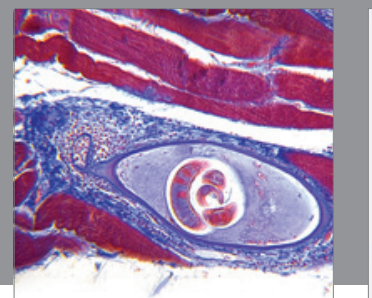

Gastroenterology

Research and Practice
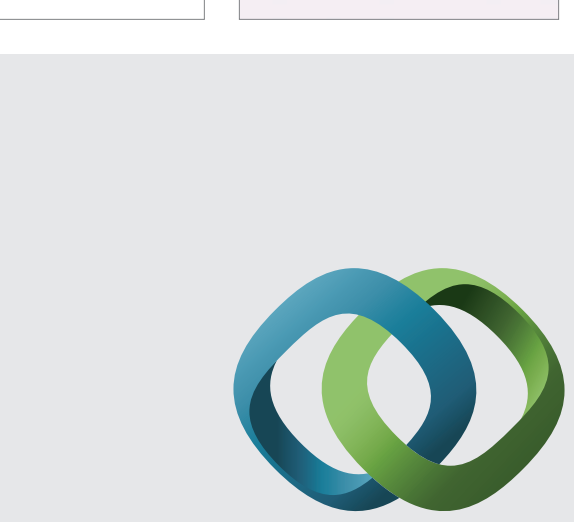

\section{Hindawi}

Submit your manuscripts at

http://www.hindawi.com
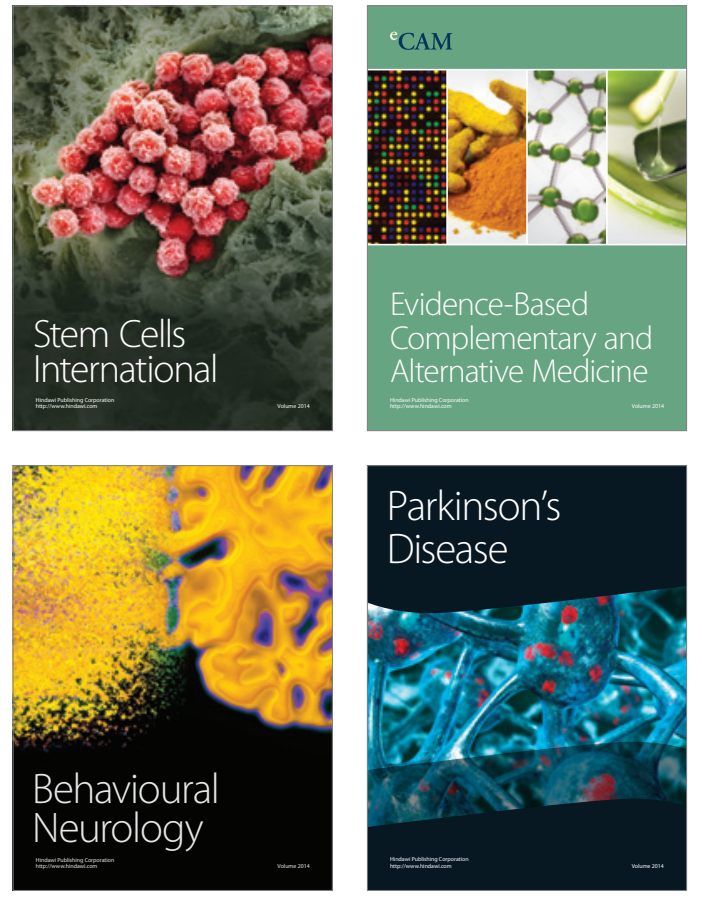
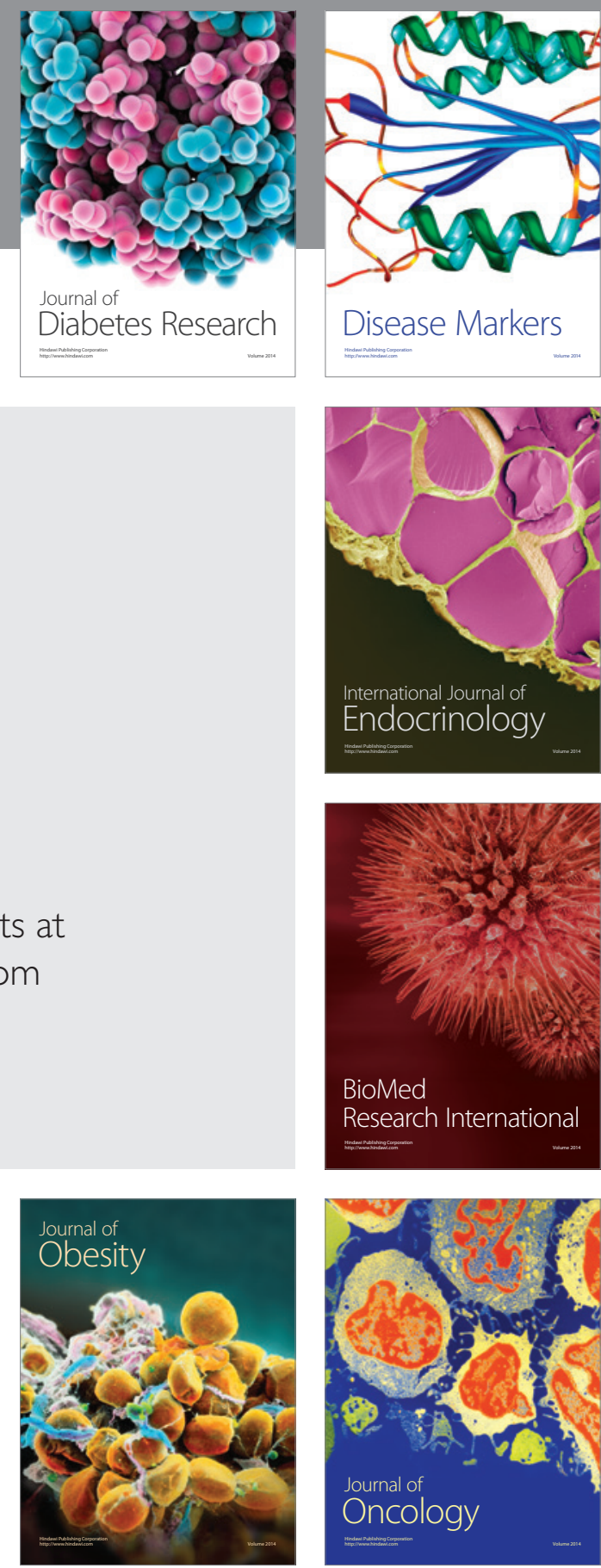

Disease Markers
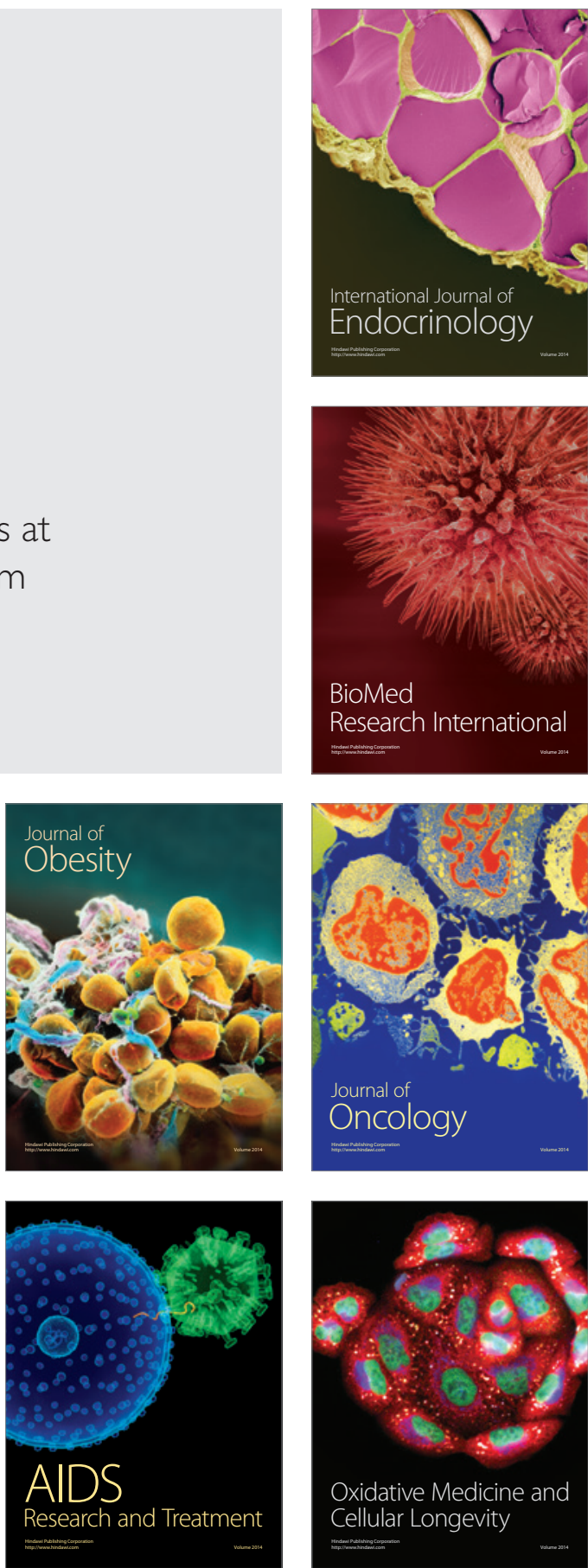